\title{
Online Food Ordering Business Models
}

\author{
Chief. Assist. Prof. PhD Desislava Grozdeva \\ University of Economics - Varna, Varna, Bulgaria \\ desislava_grozdeva@ue-varna.bg
}

\begin{abstract}
Ordering food at home or in the office is a well-established and widely available service that is commonly used by consumers, but more and more often traditional phone call gives way to the convenient and easier online form. Food selling business, in the Internet environment, undergoes radical organisational and technological changes, improving its economic and social efficiency. The relevance of the stated alternative form of sale is the basis of this article. The aim of the study is theoretically to review the existing online food ordering business models, outlining their specifics, advantages and disadvantages and based on that to examine their application and future development.
\end{abstract}

Keywords: e-business model, online food ordering, aggregator, online platforms, Internet.

JEL Code: L81; doi:10.36997/IJUSV-ESS/2019.8.2.47

\section{Въведение}

Непрекъснатото усъвършенстване на технологиите, все по-голямата адаптация на Интернет към целите на бизнеса и активното му приложение в ежедневието на потребителите водят до настъпването на съществени промени, както във фирмената дейност, така и в потребителското поведение. За да удовлетворят постоянно нарастващите си изисквания при пазаруване, да спестят време и усилия при своя избор и вземане на решение за покупка, клиентите много често се възползват от разнообразните възможности на Глобалната мрежа. Въпреки, че предимствата на Интернет се използват от електронните търговци основно за предлагане на нехранителни стоки и различни развлекателни услуги, през последните години все повече хора се ориентират към онлайн поръчки на готова храна от различните заведения за хранене. Съвременният потребител, който не разполага с достатъчно време, за да приготви храната си сам, бързо преодолява този проблем благодарение на модерните технологии и повсеместната дигитализация. Възможността за получаване на желаното меню за хапване директно у дома или в офиса посредством няколко кликвния на компютъра или на мобилния телефон е изключително удобство и за кратьк период печели много привърженици.

Повишеният интерес от страна на клиентите към този твърде лесен и практичен начин за осигуряване на любимата пица, салата или друго сготвено ястие, привлича вниманието на много ресторантьори, които откриват в тази иновативна форма на продажба допълнителен източник на приходи от своята дейност. Предлагането и доставката на готова храна до конкретен адрес с помощта на съвременни онлайн приложения създава редица нови въможности за увеличаване на конкурентоспособността и пазарния дял на съответната фирма, повишаване на лоялността и удовлетворението на клиентите. Същевременно предприемането на тази решителна крачка към дигитализация на предприятието е свързана със значителни предизвикателства относно изборьт на подходящ бизнес модел, неговото внедряване и успешно приложение; осигуряване на необходимите инвестиции; проучване на потребителските предпочитания и адаптиране спрямо тях на съответния онлайн модел.

Актуалността на посочената алтернативна форма на продажба стои в основата за разработването на настоящата статия. Целта на работата е да се направи теоретично обобщение на съществуващите бизнес модели за онлайн порьчка на готова храна, откроявайки спецификата, предимствата и недостатъците им, и въз основа на това да се изследва тяхното приложение и бъдещо развитие.

В разработката се използват данни, публикувани в платформата за статистика и 
пазарна информация Statista. За формиране на комплексна картина относно бъдещото развитие на изследвания сектор и извеждане на някои основни закономерности в него са анализирани прогнозни данни за периода 2019-2023 г.

Нарастващата популярност на онлайн продажбите на готова храна, както в глобален мащаб, така и в нашата страна, се явява важна предпоставка за тяхното задълбочено изследване в теоретичен и приложен аспект.

\section{1. Основни бизнес модели за електронна търговия}

С всяка изминала година Интернет и комуникационните технологии влияят все повече върху потребителското поведение. Работата и комуникацията, пазаруването и развлеченията, дори набавянето на предпочитаните ястия може да се осъществи бързо и безпроблемно посредством Мрежата. Необходимо условие за успешното развитие на онлайн продажбите и електронната търговия е познаването на съществуващите и прилагани в тази сфера бизнес модели, които заемат водещо място във фирмената стратегия. Във връзка с това, първоначално следва да се изясни понятието бизнес модел. Най-общо той представя начинът, по който работи предприятието и генерира печалба, като пряко засяга неговите приходи и разходи. Акцентира се върху снижаването на разходите по цялата верига на стойността и повишаване на приходите. Затова „бизнес модельт описва как организацията създава, доставя и задържа стойност" (Osterwalder et al., 2010, p. 14). Тази стойност може да се разглежда в икономически, социален, културен и друг контекст.

Като пълна и всеобхватна приемаме дефиницията на П. Тимерс (Timmers, 1998, p. 4), според която бизнес моделът обхваща:

$>$ структурата на продуктовите, сервизните и информационни потоци, която включва описание на различните бизнес играчи и тяхната роля;

$>$ описание на потенциалните ползи за отделните участници;

$>$ описание на източниците на приходи.

Следва да се обърне внимание, че „добрият бизнес модел отговаря на вечните въпроси на Питьр Дракър: Кой е клиентьт? И какво цени клиентът? Той също така отговаря на основните въпроси, които всеки мениджър трябва да си зададе: Как да печелим пари в този бизнес? Каква е основната икономическа логика, която обяснява как можем да предоставим стойност на клиентите при подходящи разходи?“" (Magretta, 2002). Разбира се, бизнес моделът дава отговор и на редица други важни въпроси, касаещи дейността на предприятието.

Съществува твърде голямо разнообразие от бизнес модели в научната литература, някои от които са изключително семпли и лесно приложими, а други са по-комплицирани и изискват специфични знания, опит и ресурси, за да се прилагат на практика. Интензивното използване на Интернет от потребителите и стопанските организациите води до изменение на съществуващите бизнес модели и същевременно до възникването на нови такива. Посочените обстоятелства изискват бързо адаптиране на фирмите и техния персонал към настъпилите промени в обкръжаващата среда, за да запазят или подобрят своята позиция на пазара. Това се отнася пряко и до бизнеса с продажба на готова храна, който в стремежа си да следва съвременните тенденции в обслужването на потребителите, налага в дейността си използването на различни дигитални устройства, улесняващи в значителна степен комуникацията с клиентите и реализирането на повече транзакции.

По своята същност бизнес моделите за е-търговия, открояват различните начини за осъществяване на търговска дейност в Интернет среда, посредством които предприятието реализира приходи и формира своята печалба. Различните бизнес модели за електронна тьрговия се формират в резултат от комбинацията на елементите на веригата на добавената стойност (както са представени от Майкъл Портър) с моделите на взаимодействие между пазарните участници в е-търговията (Timmers, 1998, p. 4). За целта е необходимо да се 
декомпозира и преструктурира веригата на добавената стойност, като се определят отделните нейни елементи и възможностите за интегриране на информацията по веригата чрез информационните технологии. Също така се изисква да се изведат възможните модели за взаимодействие на електронните пазари, които са: “един-към-един”, “много-към-един”, “един-към-много" или "много-към-много". По този начин П. Тимерс разграничава десет основни бизнес модела за електронна тьрговия: е-магазин; е-доставка; е-аукцион; е-мол; пазар при трето лице; виртуално общество; доставчик на услуги във веригата на добавената стойност; интегратори във веригата на добавената стойност; обща платформа; информационно брокерство, доверителни услуги и др. Важен принос относно класификацията на бизнес моделите в Интернет има и М. Рапа, който ги обобщава в следните категории: брокерски модел; рекламен модел; информационно посредничество; тьрговски модел; директен модел (от производителя); партньорски програми; обществени проекти; абонамент; модел „комунални услуги” (в зависимост от ползването) (Rappa, 2010). Някои от посочените модели не са толкова популярни, докато други намират значително приложение в Глобалната мрежа.

\section{2. Сыщност и особености на бизнес моделите за онлайн поръчка на готова храна}

Наличието на изключително голямо разнообразие от бизнес модели за електронна търговия потвърждава, че Интернет е среда, предоставяща широки възможности за развитие и разширяване на дейността на предприятието. Поради тази причина все повече фирми, ангажирани с продажбата на готова храна, се ориентират успешно към подготовката или прилагането на свои онлайн формати, в основата на които стоят някои от посочените по-горе бизнес модели за е-тьрговия, като е-магазин, пазар при трето лице, доставчик на услуги във веригата на добавената стойност. Разбира се, тези ключови модели са модифицирани и адаптирани спрямо спецификата на ресторантьорската дейност и очакванията на клиентите. Затова в обобщен вид могат да се откроят два базови бизнес модела при онлайн търговията с готова храна. Единият обхваща предлагането на готови ястия посредством собствения сайт, действащ като електронен магазин, а другият се отнася до функционирането на посредническите онлайн платформи за поръчка на храна, наречени агрегатори.

За да предложат пълно обслужване на своите клиенти, ресторантите и заведенията за бързо хранене прилагат софтуер за онлайн поръчване на храна. По този начин те се възползват пълноценно от предимствата на електронната търговия. Предоставя се пълна информация и богат избор на ястия и менюта, улеснява се потребителския избор посредством наличието на филтриращи и препоръчващи системи, извършва се обработка на поръчките, предоставя се възможност за електронно плащане, осъществява се анализ на статистическа информация, поддържа се обратна връзка с клиента. Важно преимущество за потребителя е прилагането на персонализиран подход при обслужването, отнасящ се до приготвяне на ястия съобразно индивидуалните изисквания и вкусовите предпочитания на купувача. Същевременно той може да избере времето, за което да бъде доставена поръчката, има право да върне храната обратно, ако не е доволен, а също да напише своя коментар в сайта относно качеството на кулинарната продукция и предлаганите услуги, бързината на доставката, дизайна и функционалната структура на сайта, степента му на актуализация и т.н. Налице са редица предимства и за собственика на сайта, предлагащ готова храна онлайн. В сравнение с поръчките, приети по телефона, при електронните такива значително намаляват грешките и недоразуменията, свързани със съдържанието на самата поръчка и адреса на получателя. Възползвайки се от онлайн покупките, заведенията за хранене реализират допълнителни приходи и достигат до по-широк пазар, като едновременно с това се постига по-ефективно използване на персонала, работното време и материалната база. Когато клиентите правят своята порьчка директно през сайта на съответното заведение, бизнесът контролира напълно целия процес от момента на нейното получаване, през 
приготвянето на храната до доставянето ѝ. Налице е непрекъснат контакт с потребителя и при възникване на евентуален проблем, веднага се реагира за неговото отстраняване.

За да се възползват напълно от този бизнес модел, заведенията следва да имат висок трафик и посещаемост на своя сайт. Наложително е да се отделят средства за реклама, с цел популяризирането му и привличане на лоялни клиенти към него, като се има предвид локалната ориентираност при онлайн продажбата на готова храна. Не трябва да се пренебрегва и необходимостта от обучен персонал за техническа поддръжка и актуализация на информацията в сайта. Предизвикателство за ресторантьорите е не само бързото приготвяне на качествени ястия, но и тяхната навременна доставка. В противен случай не може да се разчита на повторна поръчка от страна на клиента, което е от изключителна важност, предвид териториалната ограниченост относно обслужването на потребителите от конкретно заведение за хранене. Във връзка с това се изисква наличието на подходяща система за доставка. Най-често за разноса се наемат хора, разполагащи със собствен транспорт или им се предоставя такъв от самата фирма. По този начин чрез подходящо съставени маршрути се осигурява желаната бързина при доставката и се удовлетворяват потребителските изисквания.

Другият водещ бизнес модел, който се прилага при е-тьрговията с готова храна е поддържането на онлайн платформа за поръчка на кулинарна продукция. Тези платформи са известни под името агрегатори, тьй като са предназначени да обединят на едно място множество оферти на различни заведения за хранене, улеснявайки в значителна степен потребителите в процеса на търсене и избор на подходящо меню. Клиентите спестяват много време и усилия, свързани с преминаването от един сайт към друг в търсене на най-изгодното предложение. От своя страна, собствениците на заведения се възползват от генерирания висок трафик на потребители в платформата, за да увеличат продажбите си. Не са ангажирани с организиране на плащането при покупка, с техническото обезпечение и поддръжка на онлайн платформата, нито с промотирането ѝ в Интернет пространството. Концентрират се предимно върху производствените си функции, свързани с изпълнението на заявените порьчки, и евентуално върху тяхната доставка. Затова участието в такива посреднически сайтове на малки и не толкова популярни заведения е изключително важно и полезно. Така те могат да разширят обсега си на действие и да повишат информираността на потребителите относно своите предложения.

На практика в глобалната мрежа „,агрегаторите следват два основни модела: партньор и доставчик“ (Lutz et al., 2017). „И двата типа позволяват на потребителите да сравняват менютата, да преглеждат и публикуват отзиви и да правят порьчки от различни ресторанти с едно кликване“ (Hirschberg et al., 2016). Агрегаторите партньори приемат поръчките от посетителите на онлайн платформата и ги предават на съответното заведение да ги изпълни, но не се натоварват с организирането на доставката. Съсредоточават се върху клиента и персонализацията в процеса на обслужването му, като засилват потребителското изживяване и неговата удовлетвореност. Формират клиентска база данни, която използват успешно в процеса на представяне на офертите при повторно посещение на онлайн портала. При този бизнес модел се печели от таксите за извършени транзакции и за приоритетно показване на дадено ястие в резултатите от търсенията, а също от продажбата на рекламно пространство и технологии. В сравнение с него, агрегаторът доставчик реализира печалба, както от посочените по-горе източници, така и от таксата за доставка, взета от клиента, тъй като той се ангажира допълнително и с транспортирането на готовата храна до адреса на потребителя. Следователно основната разлика между двата модела, които следват онлайн платформите е в това, че агрегаторът доставчик формира своя логистична мрежа за доставка от заведенията, неразполагащи със собствен транспорт. Така той надгражда партньорския модел на еплатформата и привлича нови участници в бизнеса с онлайн продажба на готова храна. Подобен сегмент например са ресторантите с по-висока категория, които по принцип не 
изпълняват поръчки за дома или офиса, но в случай на осигурена доставка биха се включили в е-търговията. Разглежданият бизнес модел успява да привлече и част от заведенията с понисък клас и малък мащаб на дейност, които сами са организирали доставките си, но се преориентират към този тип агрегатор, поради възможността да намалят разходите си чрез аутсоринг на логистиката.

Възходът на цифровите технологии позволява реализирането на богато разнообразие от бизнес модели в условията на Интернет - някои от тях са напълно нови и непознати, а други са стари и изпитани, но адаптирани към електронната среда. Представените в теоретичен план основни бизнес модели за онлайн поръчка на храна намират реално приложение в Глобалната мрежа. Те са утвърдени и действително работещи, като създават добавена стойност за потребителя и генерират допълнителни приходи в ресторантьорството. Независимо дали ще пазаруват онлайн през уебсайта на заведението или ще направят своя избор чрез е-платформа, клиентите винаги очакват бърза доставка, вкусна храна и отлично обслужване.

\section{3. Приложение и бъдещо развитие на бизнес моделите за онлайн поръчка на готова храна}

Поръчката на храна до дома или офиса е утвърдена и масово разпространена услуга, която се използва обичайно от потребителите, но все повече традиционното обаждане по телефона с цел уточняване на меню, цени, доставка и окончателно потвърждение на поръчката, отстъпва място на удобната и предпочитана онлайн форма. Поставен в Интернет среда бизнесът с продажба на готова храна претърпява съществени организационни и технологични изменения, които водят до повишаване на неговата икономическа и социална ефективност. „Дигиталният пазар на поръчки на храна е един от най-бързо растящите сегменти на цифровата икономика по света и няма изгледи скоро това да се промени. Трансформацията на сектора се отразява на всички страни - от ресторантите до потребителите“ (Zapryanov, 2018). Ресторантите, използващи онлайн система за поръчка на храна, оптимизират цялостната си дейност относно изпълнението на управленските и производствено-стопанските функции, а клиентите, които са я предпочели, получават бързо и качествено обслужване, отговарящо в максимална степен на техните изисквания.

В глобален аспект, съгласно данните, публикувани в платформата за статистика и пазарна информация Statista, сумата на доставките на готова храна, продадена онлайн за 2018 г. възлиза на 91406 млн.щ.д., като поръчки за 47124 млн.щ.д. или 51,6\% от общата стойност са били транспортирани директно от заведенията до клиентите. Останалите поръчки, възлизащи на 44282 млн.щ.д. или 48,4\% са приети и доставени от съответните е-платформи (вж. Фиг. 1). Това показва наличието на съвсем мальк превес в световен мащаб на компаниите, предлагащи порьчка от собствен сайт или посредством агрегатори партньори над тези, прилагащи модела на т.нар. агрегатори доставчици. За следващите годни е прогнозиран стабилен ръст на световния пазар за доставка на готова храна, поръчана онлайн, като през 2023 г. стойността на доставките ще бъде 156819 млн.щ.д. Очаква се относителният дял на платформите доставчици да достигне $52,4 \%$, което утвърждава този бизнес модел вече като доминиращ. Причината е в това че, Китай и САЩ са страните, които извършват близо половината от всички доставки в световен мащаб, а в посочените държави агрегаторите доставчици имат значителен дял. Въпреки, че този модел започва да се прилага от 2013 г., т.е. доста по-късно във времето спрямо другите два, той успява много бързо да се утвърди на пазара като успешен и печеливш. Това в голяма степен се дължи на следваната експанзивна стратегия на големите международни компании, които са изградили подходяща логистична мрежа за изпълнение на доставките, възползвайки се от високата степен на гъстота на населението на азиатския пазар към който се насочват. „Четирима участници Delivery Hero, Foodpanda, GrubHub, and Just Eat - са достигнали глобален мащаб. Тези 
четирима играчи се фокусират върху различни региони... Консолидацията напредва в повечето държави и вероятно ще продължи“ (Hirschberg et al., 2016). Domino's Pizza ce утвърждава като глобален лидер при веригите заведения, които приемат поръчки през собствен сайт.

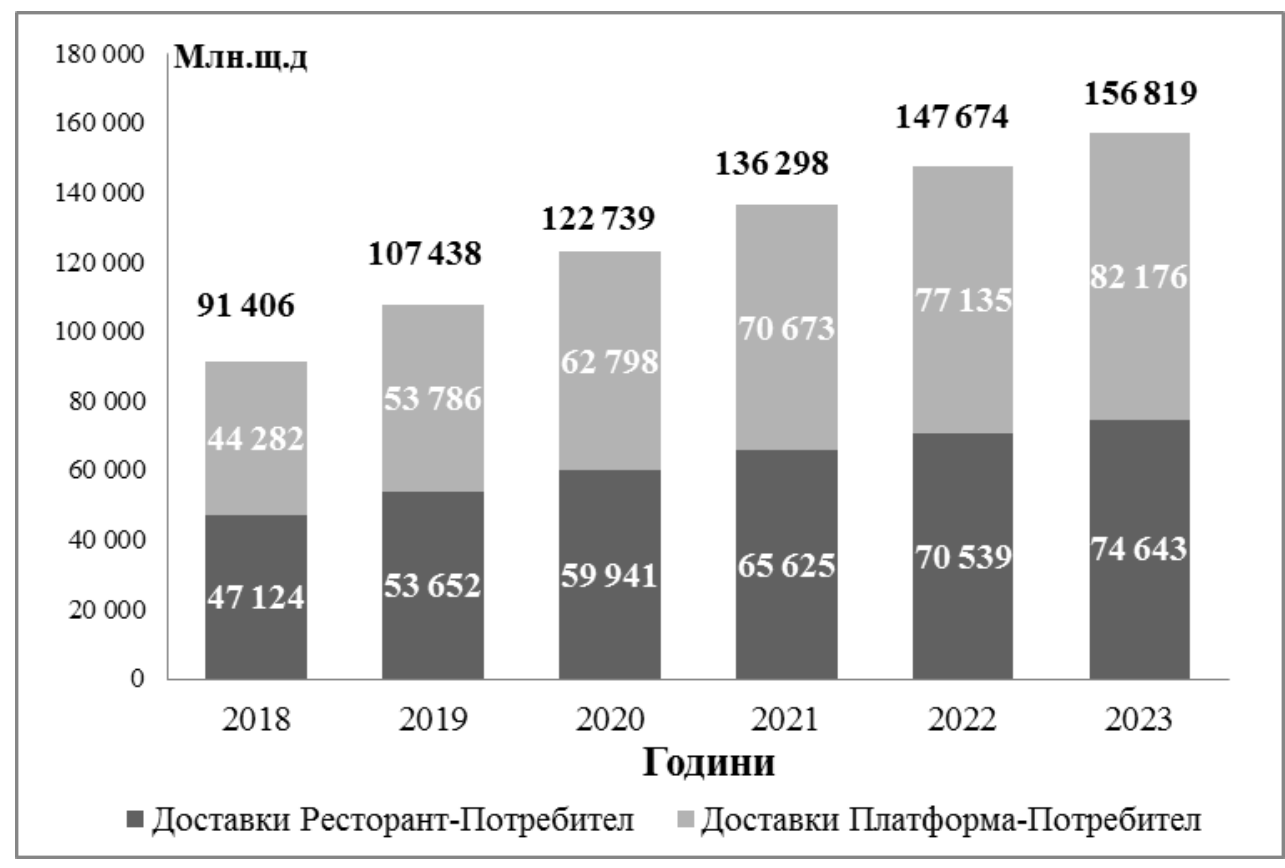

Източник: Statista, 2019.

Фигура 1. Приходи от доставките на готова храна, продадена онлайн на световния пазар за периода 2018-2023 г. в млн.щ.д. (прогноза)

По-различно от представените тенденции е положението в Европа, част от която е и нашата страна. На континента също е налице значителен растеж на доставките на готова храна, поръчана онлайн, които през 2018 г. са на стойност 14 050,1 млн.щ.д. Относителният дял на поръчаната кулинарна продукция през собствения сайт или през този на аграгатор патньор е 71,7\%, а останалите $28,3 \%$ се падат на аграгаторите доставчици (Statista, 2019). Наблюдава се съществено различие в съотношението между прилаганите модели в европейския регион. Преобладават предимно моделите за порьчка, при които ресторантите организират сами дейностите по доставката, а под една трета от поръчките са изпълнени чрез доставка от посреднически е-платформи. Недосатъчната популярност на агрегаторите доставчици на стария континент може да се обоснове с не толкова гъсто населените райони в сравнение с азиатските пазари, което прави този модел по-малко печеливш. Въпреки това с всяка изминала година той привлича повече клиенти. Същевременно високите доходи и ниво на Интернет свързаност в Западна Европа предоставят благоприятни условия за развитие на агрегаторите партньори, предлагащи богат избор на ресторанти и менюта, както и персонализация при обслужването. Великобритания, Германия и Франция са водещите държави на европейския пазар за онлайн порьчки на готова храна през 2018 г. В същата година, като пазарни лидери се отличават агрегаторите Delivery Hero, Just Eat and Takeaway.com (Statista Digital Market Outlook, 2019, p. 8). Според направена прогноза, очакванията са за постоянно нарастване на стойността на доставките на готова храна, порьчана онлайн, която ще достигне 24 659,8 млн.щ.д. през 2023 г. (Statista, 2019).

С положителен тренд се развива и българският пазар в анализирания сектор, но той е твърде незначителен и се отличава със забавяне от 4-5 години в сравнение с европейските тенденции. Все повече потребители у нас порьчват през Интернет храна от различни 
заведения, като вариант за спестяване на време за нейното приготвяне или като алтернатива на посещението в ресторант. Общата сума на реализираните през 2018 г. доставки на поръчана онлайн готова храна е 27 млн.щ.д. (Statista, 2019). Откроява се доминиращият относителен дял от 88,9\% на поръчаните ястия през сайта на заведенията или посредством агрегатор партньор. Само $11,1 \%$ от порьчките са приети от е-платформи, които самостоятелно са извършили доставките до крайните клиенти. Ограниченото прилагане на този бизнес модел в България се дължи предимно на оскъпената доставка, която те предлагат. През следващите години се очертава непрекъснато увеличаване на доставената кулинарна продукция, поръчана онлайн, като през 2023 г. тя ще възлиза на 74 млн.щ.д. Същевременно се очаква, в резултат на по-голямата им популярност и прилаганата експанзивна стратегия в страната ни, дельт на агрегаторите доставчици да се повиши до $17,6 \%$.

Извършеният кратьк обзор относно онлайн порьчките на готова храна в глобален и национален аспект, утвърждава разгледаните по-горе в теоретичен план бизнес модели като реално работещи и ефективни. Всеки един от тях има своя специфика, отличава се от останалите с конкретни предимства и недостатъци, привлича и обслужва определени клиенти. На пазара функционира успешно, както най-традиционният и утвърден модел за приемане на поръчки през собствен сайт, така и двата вида агрегатори, отличаващи се с бърз растеж и непрекъснати подобрения. Във връзка с това, могат да се изведат следните основни направления, в които ще се развиват в бъдеще разгледаните бизнес модели за онлайн поръчка на готова храна:

$>$ Утвърждаване през следващите няколко години на е-платформата агрегатор доставчик, като успешен и перспективен бизнес модел със значителен пазарен дял формираният богат избор от различни заведения и техните менюта в един портал заедно с предлагането на организирана доставка до адреса на получателя, създават голямо удобство за потребителя. Наличието на комплексно обслужване и индивидуално отношение създават висока добавена стойност за клиента, привличат неговото внимание и му предоставят очакваното онлайн изживяване.

$>$ Поддържане на вертикални и локални платформи, които обслужват конкретен продуктов или географски пазар - в ранния етап на своето развитие агрегаторите са хоризонтални, стремейки се да обхванат широко разнообразие от ресторанти и предлаганите от тях ястия. Постепенно те се разширяват твърде много, което води до претрупване на клиента с информация и затруднение при откриване на желаната храна. Появяват се т.нар. вертикални е-платформи, които се фокусират върху определена ниша, например веганска кухня, диетични и здравословни ястия, храна, приготвена само с биопродукти и т.н. Постига се голям обхват и висока удовлетвореност на конкретния сегмент.

$>$ Поява на хибридни бизнес модели - предвижда се размиване на границите между двата типа агрегатори. Все по-рядко моделите ще се прилагат в чист вид. Някои агрегатори партньори могат да разработят своя система за доставка, обогатявайки предлаганите до момента услуги в платформата. Същевременно се очаква агрегаторите доставчици да включат в листата си ресторанти, които самостоятелно транспортират поръчките си. В близко бъдеще платформите за доставка на поръчана онлайн храна ще се комбинират с есупермаркети за доставка на хранителни стоки.

$>$ Продължаване на процеса на консолидация на различните агрегатори на глобалния и на националния пазар - в резултат на интензивната конкуренция и борба за привличане на потребители се очаква с нова сила да се реализират сливания на електронни платформи за поръчка на храна, което ще изведе на преден план няколко основни участника в сектора. Те от своя страна, могат да се възползват от възможността да изградят собствена голяма логистична мрежа, която ще им позволи да извършват доставки на изгодни за клиентите цени и да утвърдят своята лидерска позиция на пазара. 
$>$ Осигуряване на персонализирано клиентско преживяване - като бизнес модел агрегаторите се открояват със способността си да изграждат голяма потребителска база, въз основа на която проучват поведението и предпочитанията на клиентите. Те изпращат персонализирани продуктови оферти и предложения за ценови намаления, адаптирани към индивидуалните потребителски изисквания. Все повече се използват възможностите на съвременните технологии като изкуствен интелект, добавена или виртуална реалност, роботика и др., които позволяват да се провежда по-активна комуникацията с клиента.

$>$ Значително улесняване на процедурата за онлайн поръчка от заведенията за хранене - компаниите ще продължат да усъвършенстват своите сайтове и е-платформи относно скорост на зареждане, оформление и навигация, като ги доближават максимално до потребителските очаквания и ги направят в най-голяма степен „юзър френдли“. Почти всеки сайт предлага на клиента опциите за доставка или за получаване на готовата поръчка на място в заведението. Непосредствено след заявяване на менюто, потребителят получава информация кога ще го получи. Той има възможност и за проследяване на самата доставка.

$>$ Използване на всички възможни канали и устройства за извършване на поръчка, независимо от прилагания бизнес модел - тъй като все повече потребители ползват различни мобилни устройства, като таблети и смартфони, за да търсят информация или да направят онлайн своята покупка, задължително всеки сайт за поръчка храна трябва да има подходяща мобилна версия, която е удобна за клиента. Същевременно потребителят може да поръча желаното меню през социалните мрежи (Facebook, Twitter), които той всеки ден посещава, споделя информация или изказва мнение в тях. Кьм настоящия момент вниманието на мениджърите е привлечено от различните преимущества при използването на чатботове за обслужване на клиентите при поръчване на готова храна през платформите за изпращане на съобщения като Facebook Messenger, Viber, Skype. Чатботовете успешно заместват приложението за поръчка на съответния ресторант, спестявайки време и свободно пространство в мобилния телефон. Те са изключително ефективни при получаване на еднотипни въпроси, на които се дават стандартизирани отговори, без да се изисква наличие на персонал. Могат да обслужват едновременно много клиенти, като комуникират чрез текстови съобщения, устна реч или емотикони. Постепенно се популяризира извършването на поръчка посредством различни смарт устройства - смарт часовник, смарт телевизор, смарт устройство за гласова поръчка в автомобила.

Непрекъснатият напредък на технологиите и нарастващите потребителски изисквания водят до усъвършенстване на съществуващите модели за онлайн поръчка на готова храна, до появата на хибридни модели или нови такива в близките години. Динамичното развитие на изследвания сектор намира израз в процесите на консолидация в глобален и национален мащаб на различни участници, което е свързано с последващи промени в пазарните дялове и в лидерските позиции. Очаква се офертите, отправени към потребителите да бъдат все поперсонализирани относно предлаганите ястия и техните цени, налични промоции и допълнителни услуги, с цел подобряване на обслужването и цялостното клиентско преживяване.

\section{Заключение}

За голяма част от заведенията за хранене приемането на онлайн поръчки се явява реална възможност за получаване на допълнителни приходи и по-ефективно използване на наличните ресурси. Същевременно прилагането на определен е-бизнес модел изисква значителни инвестиции в технологии, цялостна реорганизация на дейността и осигуряване на подходяща логистична мрежа. Независимо дали ресторантьт поддържа собствен сайт или се възползва от услугите на агрегаторите партньори или доставчици, това е начинът той да бъде конкурентоспособен на пазара. Продажбите на готова храна през Интернет нарастват много бързо, поради динамичния начин на живот, липсата на свободно време и тьрсенето на 
разнообразие в менюто. В условията на дигитализация потребителите изискват богат избор, високо качество на храната, изгодни цени и навременна доставка. Затова всяко заведение следва да подбере своя бизнес модел така, че да успее да удовлетвори клиентите си в найвисока степен.

\section{References}

1. Lutz, T., Bolden, D., Melker, K. and Martin, M. (2017). How Digital Delivery Puts the Restaurant Value Chain Up for Grabs, 17 January 2017. [Online] Available from: https://www.bcg.com/publications/2017/technology-digital-how-digital-delivery-puts-therestaurant-value-chain-up-for-grabs.aspx [Accessed: 06/10/2019].

2. Hirschberg, C., Rajko, A., Schumacher, T. and Wrulich, M. (2016). The Changing Market for Food Delivery, November 2016. [Online] Available from: https://www.mckinsey.com/industries/high-tech/our-insights/the-changing-market-for-fooddelivery [Accessed: 06/10/2019].

3. Magretta, J. (2002) Why Business Models Matter. Harvard Business Review, May 2002 [Online]. Available from: https://hbr.org/2002/05/why-business-models-matter\#commentsection [Accessed: 03/10/2019].

4. Osterwalder, A. and Pigneur, Y. (2010) Business Model Generation, Published by John Wiley \& Sons, Inc., Hoboken, New Jersey, USA.

5. Rappa, M. (2010) Business Models on the Web. [Online] Available from: http://digitalenterprise.org/models/models.html [Accessed: 04/10/2019].

6. Statista (2019). Revenue forecast for the Online Food Delivery market worldwide from 2017 to 2023, 2019. [Online] Available from: https://www.statista.com/statistics/891078/online-fooddelivery-revenue-by-segment-worldwide [Accessed: 06/10/2019].

7. Statista (2019). Revenue forecast for the Online Food Delivery market in Europe from 2017 to 2023, 2019. [Online] Available from: https://www.statista.com/statistics/696525/online-fooddelivery-revenue-by-segment-in-europe [Accessed: 06/10/2019].

8. Statista (2019). Revenue in the Online Food Delivery market in Bulgaria, 2019. [Online] Available from: https://www.statista.com/outlook/374/130/online-fooddelivery/bulgaria\#market-revenue [Accessed: 06/10/2019].

9. Statista Digital Market Outlook (2019). Online Food Delivery Report 2019, 2019. [Online] Available from: https://www.statista.com/study/42306/eservices-report [Accessed: 06/10/2019].

10. Timmers, P. (1998) Business Models for Electronic Markets. Journal Electronic Markets, 8 (2), pp. 3-8.

11. Zapryanov, Y. (2018). Bitkata za digitalnata hrana. Onlayn porachkite ot restoranti i zavedeniya za barzo hranene promenyat sektora izosnovi, Kapital, 4 May 2018. [Online] Available from: https://www.capital.bg/biznes/kompanii/2018/05/04/3172951_bitkata_za_digitalnata_hrana/ [Accessed: 07/10/2019]. 